\title{
Komposisi Spesies Penggerek Batang Padi dan Parasitoid Telurnya pada Ketinggian Tempat yang Berbeda
}

\author{
I NYOMAN WIJAYA*), WAYAN ADIARTAYASA, DAN \\ KETUT AYU YULIADHI
}

\author{
Program Studi Agroekoteknologi Fakultas Pertanian Universitas Udayana \\ J1. PB. Sudirman Denpasar 80326 Bali \\ ${ }^{*}$ E-mail: wijayainyoman1956@gmail.com
}

\begin{abstract}
Composition of Rice Stem Borer Species and Their Egg Parasitoids at Different Altitudes. Rice stem borer is one of the main pest of rice plants that always percolating and attack plants in the field. The pests can result in damage to plants and lost of the grain from season to season. The aim of this research is to know composition and dominance rice stem borer species and role of their eggs parasitoid at an altitude of different places. Research is done by survey based on the height of different altitude in rice plants two weeks after cropping up until eleven weeks after planting. Research conducted from April until August 2019 in rice field that belonging to farmers at Subak Cemagi Let, Cemagi Village and Subak Teba, Mengwi village, Badung regency, Bali province. Subak Cemagi Let are at an altitude of 15 meters above sea level whereas Subak Teba are at an altitude of 300 meters above sea level. Identification of Rice stem borer larvae and their eggs parasitoid done in Pest Laboratory, Agriculture Faculty of Udayana University. Found three species rice stem borer in the height $15 \mathrm{mdpl}$ namely Scirpophaga incertulas; Sesamia inferens dan Chilo suppressalis, whereas in the height $300 \mathrm{mdpl}$ found four species namely Scirpophaga incertulas, Sesamia inferens, Chilo suppressalis, dan Chilo polychrysus. S. incertulas was the most dominant at the two different altitude. Three species of eggs parasitoid that have role to suppress the development of rice stem borer at the different altitude namely Tetrastichus schoenobii, Telenomus rowani dan Trichogramma japonicum. T. schoenobii was the most dominant to suppress rice stem borer populations.
\end{abstract}

Keywords: rice stem borer, eggs parasitoid, altitude

\section{PENDAHULUAN}

Penggerek batang padi merupakan salah satu hama utama tanaman padi. Intensitas serangannya dapat mencapai $90 \%$ dan kerugian hasil yang diakibatkan oleh hama tersebut mencapai 125.000 ton per musim tanamnya (Soejitno, 1984). Di Bali pada tahun 2001-2014 luas serangannya berturut-turut mencapai $1.105 ; 1.672,2$; $1.689,5 ; 1.872 ; 1.724,5 ; 2.673,5 ; 1.265,15$; 823,$55 ; 1.223,25 ; 763,55 ; 639,4 ; 904,15$ dan 612,40 ha dengan intensitas serangan ringan sampai berat (BPTPH Bali, 2014) 
I NYOMAN WIJAYA et al. Komposisi Spesies Penggerek Batang Padi dan Parasit...

Suharto dan Sembiring (2007) menjumpai enam spesies penggerek batang padi di Indonesia. Semua spesies tersebut termasuk ordo Lepidoptera, lima spesies dari famili Pyralidae dan satu spesies dari famili Noctuidae. Ke enam spesies tersebut adalah penggerek batang padi kuning Scirpophaga incertulas Walker (Lepidoptera: Pyralidae), penggerek batang padi putih Scirpophaga innotata Walker (Lepidoptera: Pyralidae), penggerek batang padi bergaris Chilo suppressalis Walker (Lepidoptera: Pyralidae), penggerek batang padi kepala hitam Chilo polychrysus Meyrick (Lepidoptera: Pyralidae), penggerek batang padi berkilat Chilo auricillius Dudgeon (Lepidoptera: Pyralidae) dan penggerek batang padi merah jambu Sesamia inferens Walker (Lepidoptera: Noctuidae). Spesiesspesies tersebut mempunyai perilaku yang sama dalam menyerang tanaman. Namun penelitian kami hanya menemukan empat spesies penggerek batang padi di Bali yaitu S. incertulas, S. inferens, C. suppressalis dan C. polychrisus (Wijaya \& Adiartayasa, 2015).

Sampai saat ini upaya pengendalian yang dilakukan petani masih mengandalkan insektisida, karena efisien waktu dan tenaga. Namun demikian, penanganan yang tidak tepat dapat menyebabkan hama sasaran menjadi resisten, musuh alami terbunuh sehingga laju pertumbuhan populasi hama meningkat serta menyebabkan keracunan dan pencemaran lingkungan (Kartohardjono, 2011; Makarim et al., 2003). Alternatif lain yang dapat dipilih untuk mengatasi masalah hama tersebut adalah dengan menerapkan konsepsi pengendalian hama terpadu (PHT) yakni pengendalian secara terintegrasi dan ramah lingkungan. Pengendalian hayati dengan pemanfaatan musuh alami (parasitoid, predator dan patogen) merupakan satu komponen utamanya. Musuh alami dapat dimanfaatkan dalam program pengendalian hayati karena musuh alami sudah tersedia di alam, selektivitas tinggi dan tidak menimbulkan hama baru, dapat berkembangbiak dan menyebar, dapat mencari dan menemukan inang sehingga pengendalian berjalan dengan sendirinya serta dapat dilakukan dalam jangka panjang. Penelitian kami menemukan tiga spesies parasitoid telur yang berperan menekan perkembangan penggerek batang padi di Bali yaitu Trichogramma japonicum Ashmead (Hymenoptera

Trichogrammatidae), Telenomus rowani (Gahan) (Hymenoptera : Scelionidae), dan Tetrastichus schoenobii Ferriere (Hymenoptera : Eulopidae) (Wijaya, 1992). 
Penelitian ini bertujuan untuk : 1). perkembangan parasitoid telur penggerek mengetahui komposisi spesies penggerek batang padi yang menyerang tanaman padi pada ketinggian tempat berbeda, 2) mengetahui komposisi spesies-spesies parasitoid telur penggerek batang padi pada ketinggian tempat berbeda 3) menganalisis parasitoid yang paling berperan dalam menekan perkembangan penggerek batang padi pada ketinggian tempat berbeda.

\section{BAHAN DAN METODE}

Penelitian ini dilaksanakan bulan April 2019 sampai dengan bulan Agustus 2019 pada pertanaman padi milik petani di Subak Cemagi Let Desa Cemagi, Kecamatan Mengwi, Kabupaten Badung, Provinsi Bali dan Subak Teba, Desa Kapal, Kecamatan Mengwi, Kabupaten Badung, Provinsi Bali. Subak Cemagi Let berada di ketinggian 15 meter diatas permukaan laut (0 -250 mdpl), sedangkan di Subak Teba berada di ketinggian 300 meter diatas permukaan laut $(250-500 \quad$ mdpl $)$. Identifikasi larva penggerek batang padi dan parasitoid telurnya dilakukan di Laboratorium Hama Tumbuhan Fakultas Pertanian dan Laboratorium Sumber Daya Genetik Universitas Udayana.Laboratorium Makanan Ternak Fakultas Peternakan Universitas Udayana untuk merekam

batang padi.

Penelitian dilakukan dengan metode survei berdasarkan ketinggian tempat pada tanaman padi varietas Ciherang berumur dua minggu setelah tanam sampai sebelas minggu setelah tanam, sehingga dilakukan sepuluh kali pengamatan. Informasi cara bertanam petani dan daerah yang sering terserang hama penggerek batang padi diperoleh dari Dinas Pertanian Tanaman Pangan dan Holtikultura Kabupaten Badung. Kemudian diadakan survei pendahuluan di daerah yang terserang penggerek batang padi tersebut. Dari hasil survei ditetapkan persawahan yang digunakan sebagai lokasi penelitian. Pada masing-masing ketinggian tempat diambil larva penggerek batang padi dan telur pengggerek batang padi sebagai bahan penelitian.

Pengambilan sampel untuk menentukan komposis spesies penggerek batang padi dilakukan secara acak pada lahan pertanaman padi di ketinggian tempat yang berbeda. Pada ketinggian tempat yang berbeda diambil 100 larva penggerek batang padi. Pengambilan sampel dilakukan setiap minggu mulai dari tanaman padi berumur dua minggu setelah tanam sampai sebelas minggu setelah tanam (sepuluh kali 


\section{NYOMAN WIJAYA et al. Komposisi Spesies Penggerek Batang Padi dan Parasit...}

pengambilan sampel), dengan melihat gejala serangan pada tanaman padi. Tanaman padi yang bergejala dipotong pangkal batangnya kemudian dibelah, apabila terdapat larva penggerek batang padi, diambil dan dimasukkan ke dalam botol yang berisi alkohol 90\%, pada botol diberi label lokasi dan tanggal pengambilan sampel. Selanjutnya diidentifikasi menggunakan cara yang dilakukan oleh Siwi (1979) di Laboratorium Hama, Fakultas Pertanian, Universitas Udayana.

Pengamatan kelimpahan parasitoid telur penggerek batang padi dilakukan dengan cara mengumpulkan telur-telur penggerek batang padi sebanyak 20 kelompok setiap pengamatan di masingmasing ketinggian yang berbeda. Kelompok telur yang terkumpul tersebut masingmasing dimasukkan ke dalam tabung gelas dan dipelihara, kemudian setelah menetas diamati spesies dan populasi parasitoidnya. Identifikasi parasitoid dilakukan di bawah mikroskup menggunakan kunci determinasi serangga oleh Kalshoven (1981). Persentase parasitoid telur penggerek batang padi dihitung dengan cara yang disarankan oleh Nishida \& Torii (1970). Identifikasi dan perkembangan parasitoid dilakukan di Laboratorium Sumber Daya Genetik Universitas Udayana. Dalam penelitian ini parasitoid dihitung dalam persen terhadap jumlah telur-telur semula atas dasar banyaknya larva penggerek batang padi dan parasitoid yang menetas. Oleh karena seekor Tetrastichus sp. dapat menghabiskan rata-rata tiga telur penggerek batang padi dan dua ekor Trichogramma sp. menetas dari satu telur penggerek batang padi, maka persentase parasitoid dapat dihitung sebagai berikut :

$3 a$ x $100 \%$

$3 a+(1 / 2) b+c+d$ untuk menghitung a dimana :

a : Tetrastichus sp. b : Trichogramma sp.

c : Telenomus sp. d : larva penggerek batang padi

Rumus tersebut merupakan contoh apabila dari satu kelompok telur penggerek batang padi menetas tiga spesies parasitoid dan larva penggerek batang padi
Data yang diperoleh dianalisis secara deskriptif. Data hasil analisis disajikan dalam bentuk tabel dan gambar. 


\section{HASIL DAN PEMBAHASAN}

Ditemukan tiga spesies penggerek batang padi di Subak Cemagi Let ketinggian $<250$ mdpl yaitu $S$. incertulas ; S. inferens dan Chilo suppressalis (Gambar 1), sedangkan di Subak Teba ketinggian $>250$ mdpl ditemukan empat spesies yaitu $S$. incertulas; S. inferens ; C. suppressalis, dan C. polychrysus. S. incertulas merupakan spesies yang dominan di kedua ketinggian berbeda (Gambar 2). Hasil penelitian Wijaya (1992), juga menemukan S. incertulas merupakan spesies yang paling dominan di Kabupaten Badung. Ternyata selama 27 tahun $S$. incertulas selalu mendomonasi keberadaan penggerek batang padi di Kabupaten Badung. Menurut Suharto \& Usyati (2009) di daerah tropis, penanaman padi secara terus-menerus sepanjang tahun menyebabkan $S$. incertulas akan terus berkembang, sehingga dalam satu tahun terdapat $7-8$ generasi. Spesies penggerek batang padi yang beradaptasi pada satu agroekosistem akan menjadi spesies yang dominan. Rataan populasi S. incertulas selama 10 kali pengamatan $74,4 \%$ sampai $78,1 \%$., sedangkan populasi S. inferens $20 \%$. Selanjutnya didapatkan bahwa $90 \%$ penggerek batang padi adalah $S$. inferens dan sisanya penggerek batang padi merah jambu (S. inferens ). Pengamatan minggu pertama yaitu pada umur tanaman dua minggu setelah tanam populasi $S$. incertulas sangat tinggi baik pada ketinggian $>250$ mdpl maupun ketinggian < 250 mdpl, namun cenderung mengalami penurunan dengan meningkatnya umur tanaman, sebaliknya spesies $S$. inferens mengalami peningkatan sesuai peningkatan umur tanaman.

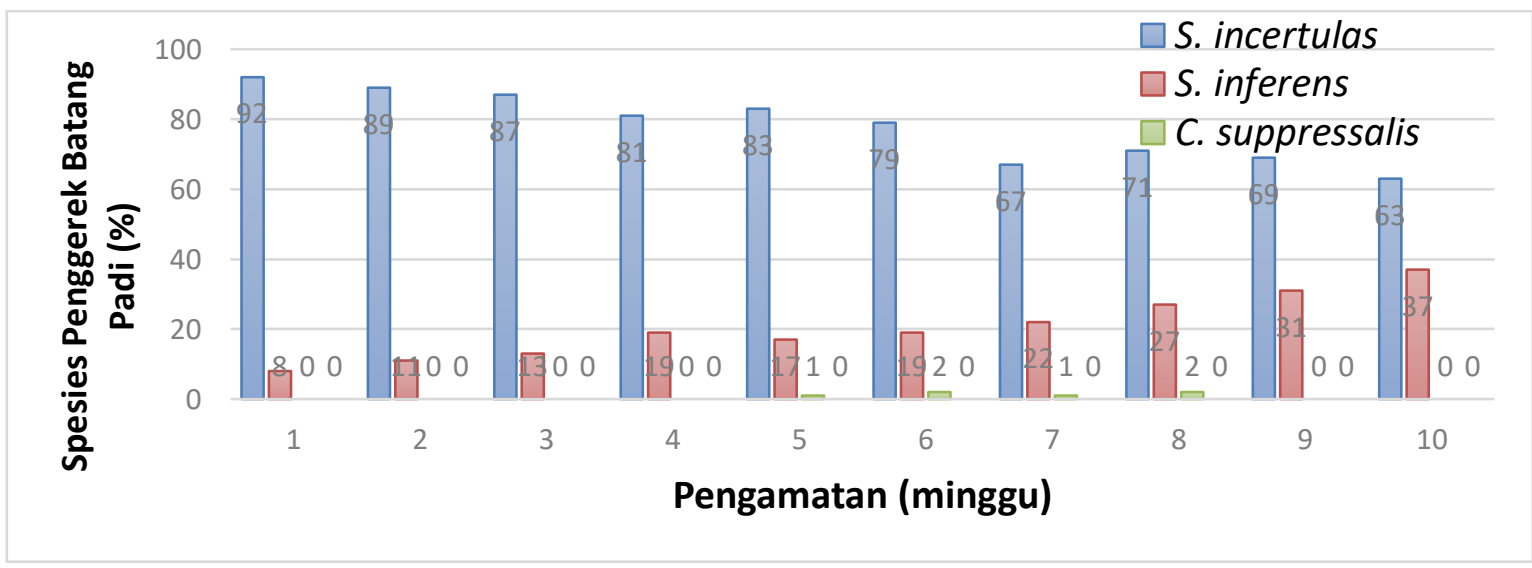

Gambar 1. Komposisi Spesies Penggerek Batang Padi di Subak Cemagi Let Ketinggian < $250 \mathrm{mdpl}$ 
I NYOMAN WIJAYA et al. Komposisi Spesies Penggerek Batang Padi dan Parasit...

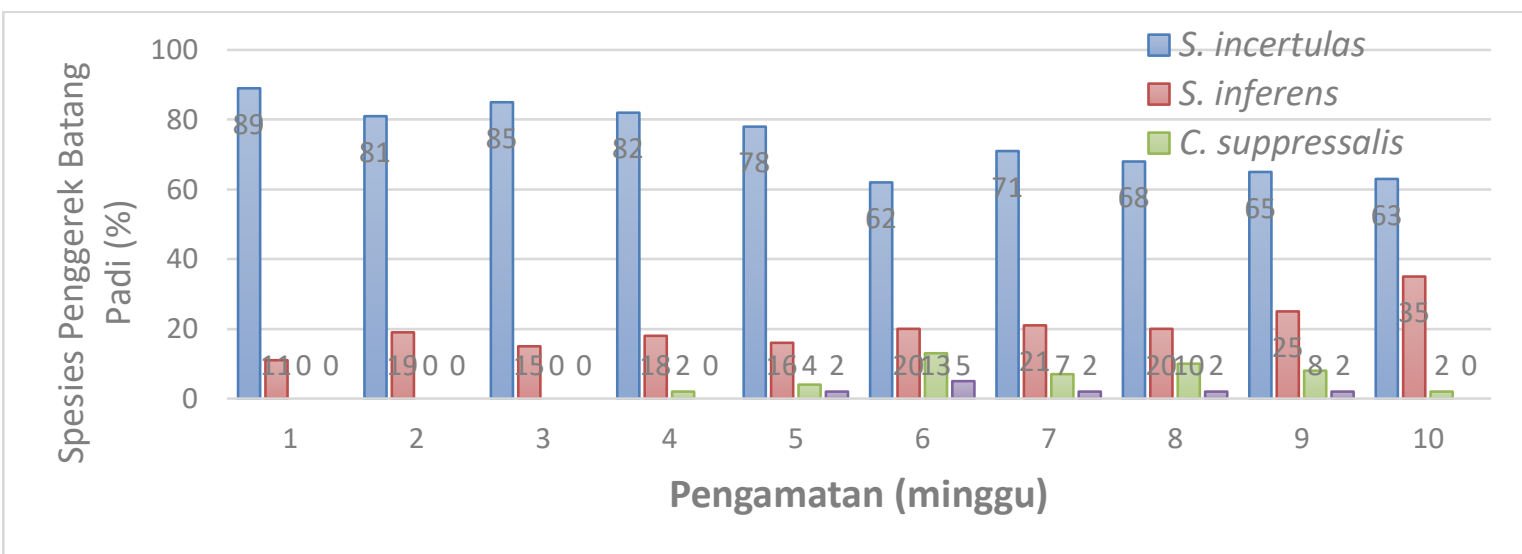

Gambar 2. Komposisi Spesies Penggerek Batang Padi di Subak Teba Ketinggian > 250 mdpl

Hasil penelitian menunjukkan tiga jenis parasitoid yang memarasit telur penggerek batang padi baik di Subak Cemagi Let (15 mdpl) maupun di Subak
Teba (300 mdpl). Tiga spesies parasitoid telur tersebut yaitu $T$. japonicum. $T$. rowani dan T. schoenobii (Gambar 3 dan Gambar 4).

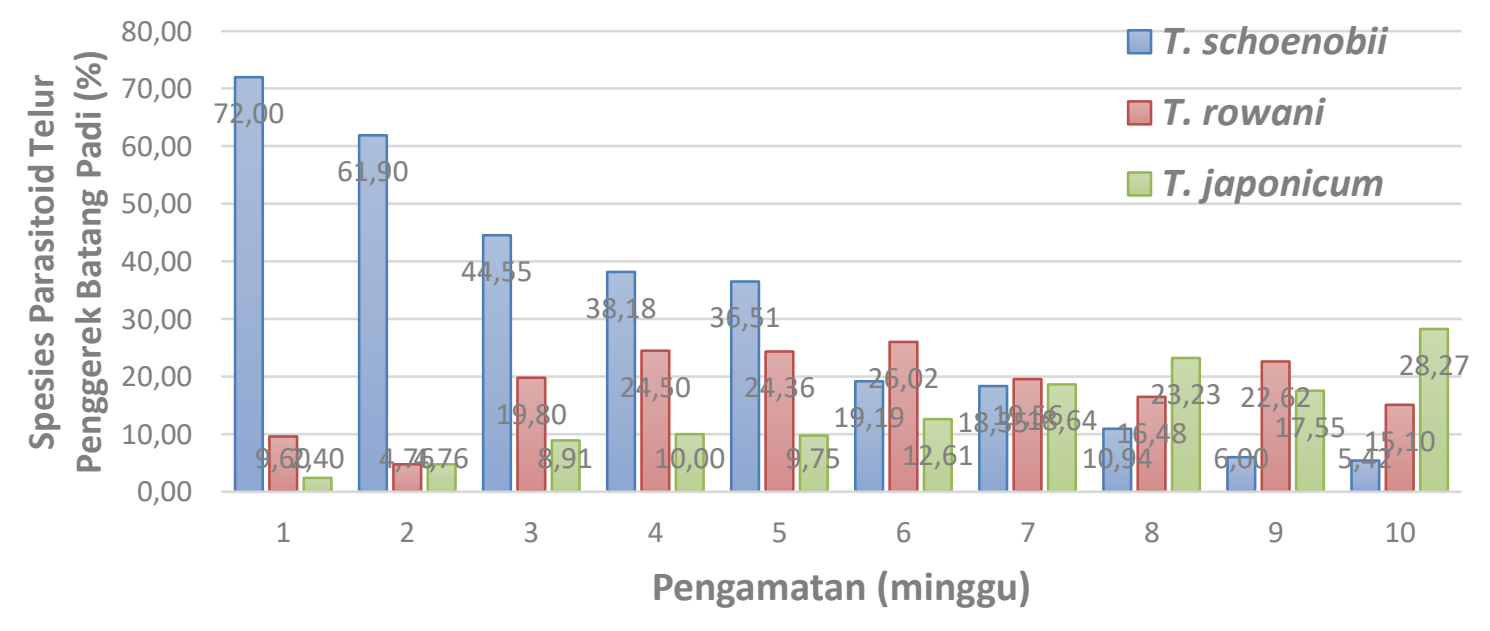

Gambar 3. Komposisi Parasitoid Telur Penggerek Batang Padi di Subak Cemagi Let $(<250$ mdpl) 


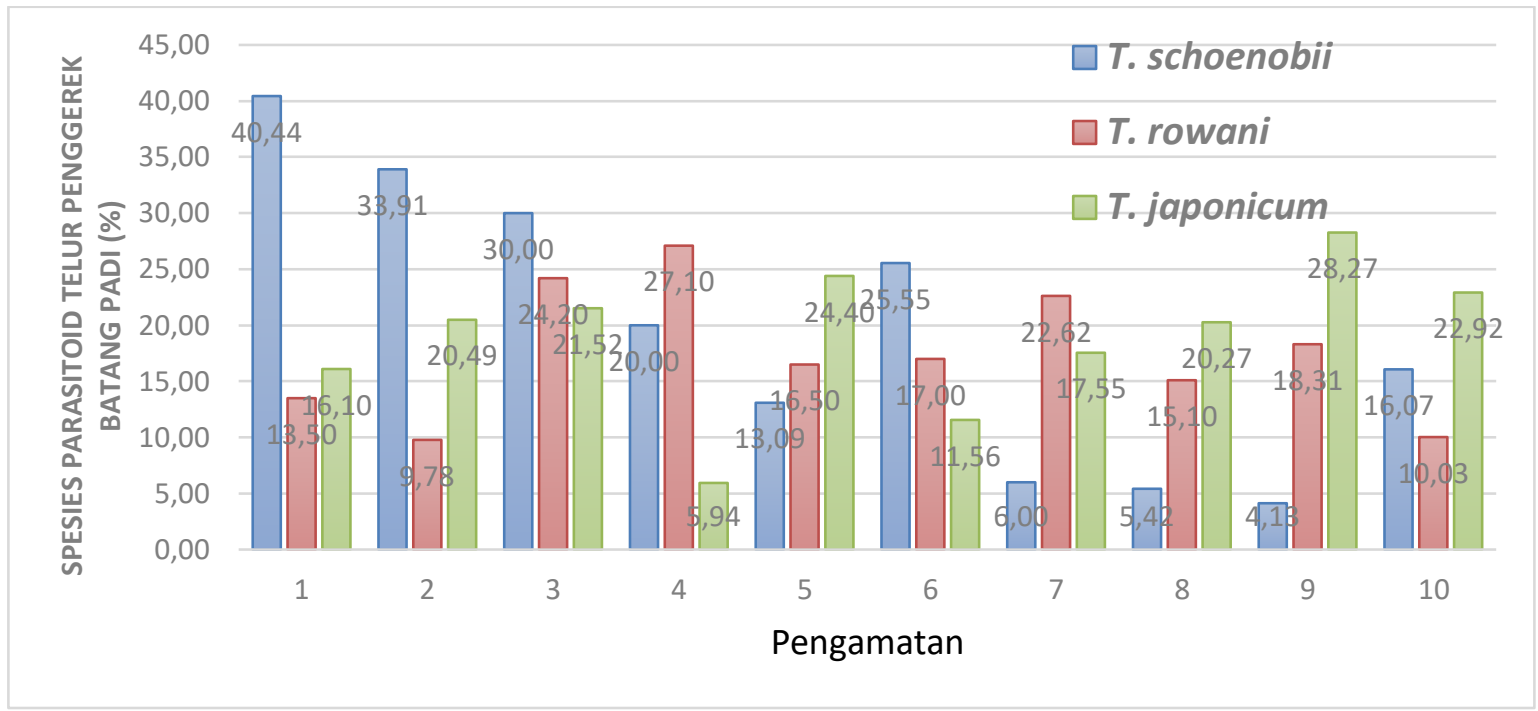

Gambar 4. Komposisi Parasitoid Telur Penggerek Batang Padi di Subak Teba (300 mdpl)

Rataaan daya parasitisasi parasitoid telur penggerek batang padi lebih tinggi di dataran rendah $(63,11 \%)$ dibandingkan dataran lebih tinggi $(37,50 \%)$ (Tabel 1.). Pada dataran rendah (ketinggian $15 \mathrm{mdpl}$ ) selama sepuluh kali pengamatan menunjukkan parasitoid T. schoenobii mendominasi dibandingkan yang lain. Peranan parasitoid T. schoenobii paling tinggi pada tanaman berumur dua minggu setelah tanam, kemudian terus menurun mengikuti bertambahnya umur tanaman, sedangkan $T$. rowani dan T. japonicum perannya cendrung meningkat dengan bertambahnya umur tanaman. Pada ketingggian $300 \mathrm{mdpl}$ parasitoid telur $T$. schoenobii perannya lebih tingggi dibandingkan spesies yang lainnya. 
I NYOMAN WIJAYA et al. Komposisi Spesies Penggerek Batang Padi dan Parasit...

Tabel 1. Komposisi Parasitoid Telur Penggerek Batang Padi pada Ketinggian Tempat yang Berbeda

\begin{tabular}{|c|c|c|c|c|c|c|c|c|}
\hline \multirow{3}{*}{$\begin{array}{l}\text { Pengamatan } \\
\text { minggu ke }\end{array}$} & \multirow{2}{*}{\multicolumn{4}{|c|}{$\begin{array}{c}\text { Subak Cemagi Let }(<250 \mathrm{mdpl}) \\
\text { Spesies Parasitoid telur Penggerek } \\
\text { batang padi }(\%)\end{array}$}} & \multicolumn{4}{|c|}{ Subak Teba (>250 mdpl) } \\
\hline & & & & & Spesie & $\begin{array}{r}\text { Parasito } \\
\text { batang }\end{array}$ & $\begin{array}{l}\text { telur Pe } \\
\text { di }(\%)\end{array}$ & ggerek \\
\hline & $\mathrm{a}$ & $\mathrm{b}$ & $\mathrm{c}$ & Jumlah & $\mathrm{a}$ & $\mathrm{b}$ & $\mathrm{c}$ & Jumlah \\
\hline 1 & 72,00 & 9,60 & 2,40 & 84,00 & 40,44 & 13,50 & 16,10 & 70,04 \\
\hline 2 & 61,90 & 4,76 & 4,76 & 71,42 & 33,91 & 9,78 & 20,49 & 64,18 \\
\hline 3 & 44,55 & 19,80 & 8,91 & 73,26 & 30,00 & 24,20 & 21,52 & 75,72 \\
\hline 4 & 38,18 & 24,5 & 10,00 & 72,68 & 20,00 & 27,10 & 5,94 & 53,04 \\
\hline 5 & 36,51 & 24,36 & 9,75 & 70,69 & 13,09 & 16,50 & 24,40 & 53,99 \\
\hline 6 & 19,19 & 26,02 & 12,61 & 57,82 & 25,55 & 17,00 & 11,56 & 54,11 \\
\hline 7 & 18,35 & 19,56 & 18,64 & 56,55 & 6,00 & 22,62 & 17,55 & 46,17 \\
\hline 8 & 10,94 & 16,48 & 23,23 & 50,65 & 5,42 & 15,10 & 20,27 & 48,79 \\
\hline 9 & 6,00 & 22,62 & 17,55 & 46,17 & 4,13 & 18,31 & 28,27 & 45,36 \\
\hline 10 & 5,42 & 15,10 & 28,27 & 48,79 & 16,07 & $10,, 03$ & 22,92 & 38,77 \\
\hline Jumlah & 313,14 & 182,79 & 136,12 & 631,06 & 194,51 & 174,14 & 181,42 & 375,01 \\
\hline Rataan & 31,31 & 18,18 & 13,61 & 63,11 & 19,45 & 17,41 & 18,14 & 37,50 \\
\hline
\end{tabular}

Keterangan :

$$
\text { a :T. schoenobii } \quad \text { b : T. rowani } \quad \text { c : T. japonicum }
$$

\section{SIMPULAN}

Berdasarkan hasil penelitian dapat disimpulkan beberapa hal yaitu ditemukan tiga spesies penggerek batang padi di ketinggian 15 mdpl yaitu Scirpophaga incertulas; Sesamia inferens dan Chilo suppressalis, sedangkan di ketinggian 300 mdpl ditemukan empat spesies yaitu Scirpophaga incertulas, Sesamia inferens, Chilo suppressalis, dan Chilo polychrysus. S. incertulas merupakan spesies yang dominan di kedua ketinggian berbeda. Tiga spesies parasitoid telur penggerek batang padi ditemukan baik di ketinggian $15 \mathrm{mdpl}$ maupun 300 mdpl. Ke tiga parasitioid telur tersebut adalahyang berperan menekan perkembangan pengggerek batang padi pada ketinggian tempat yang berbeda yaitu: Tetrastichus schoenobii, Telenomus rowani dan Trichogramma japonicum. $T$. schoenobii merupakan spesies yang paling dominan menekan populasi penggerek batang padi.

\section{DAFTAR PUSTAKA}

BPTPH Bali, B. P. T. P. H. (2014). Laporan Pelaksana Kegiatan Balai Proteksi Tanaman Pangan Tahun Anggaran 2013/2014. 
Kalshoven, L. G. E. (1981). The Pests of Crops in Indonesia L.G.E.Kalshoven; Revised and Translated by P.A.Van Der Laan. PT. Ichtiar Baru-Van Hoeve.

Kartohardjono, A. (2011). Penggunaan Musuh alami Komponen Pengendalian Hama Padi Berbasis Ekologi. Pengembangan Inovasi Pertanian, 4(April 2009), 29-46.

Makarim, A. K., Widiarta, I. N., Hendarsih, S., \& Abdurachman, S. (2003). Panduan teknis pengelolaan hara dan pengendalian hama penyakit tanaman padi secara terpadu. Puslitbangtan.

Nishida, T., \& Torii, T. (1970). A handbook of field methods for research on rice stem-borers and their natural enemies (IBP handbook no. 14). Davis.

Siwi, S. S. (1979). Identifikasi Penggerek Batang Padi Di Indonesia. Kongres Entomologi I Jakarta.

Soejitno, J. (1984). The Biological Aspects of Egg-Parasitoids of Rice Stemborer. Dalam Sosromarsono. S. et al. (Ed.), Symposium on Biological Control of Pests in Tropical Agricultural Ecosystem.

Suharto, H., \& Sembiring, H. (2007). Status Hama Penggerek Batang Padi di Indonesia.

Suharto, H., \& Usyati, N. (2009). Pengendalian Hama Penggerek Batang Padi. Balai Besar Penelitian Tanaman Padi.

Wijaya, I. N. (1992). Serangan dan Musuh Alami Penggerek Batang Padi pada Persawahan Tanam Serentak dan Tidak Serentak di Kabupaten Badung, Provinsi Bali. Institut Pertanian Bogor.

Wijaya, I. N., \& Adiartayasa, W. (2015). Serangan Penggerek Batang Padi dan Peran Parasitoid Telurnya dalam Mengendalikannya. 